\title{
Thin layer drying kinetics of lemon verbena leaves: A quality assessment
}

\section{and mathematical modeling}

\author{
Javid Ghasemi ${ }^{1}$, Mehdi Moradi ${ }^{1 *}$, Sayed Hossein Karparvarfard ${ }^{1}$, Mohammad Taghi Golmakani ${ }^{2}$, \\ Amin Mousavi Khaneghah ${ }^{3, *}$
}

${ }^{1}$ Department of Biosystems Engineering, School of Agriculture, Shiraz University, Shiraz, Iran; ${ }^{2}$ Department of Food Science and Technology, School of Agriculture, Shiraz University, Shiraz, Iran; ${ }^{3}$ Department of Food Science and Nutrition, Faculty of Food Engineering, University of Campinas (UNICAMP), Rua Monteiro Lobato, 80. Caixa Postal: 6121.CEP: 13083-862, Campinas, São Paulo, Brazil

*Corresponding authors: Mehdi Moradi, Department of Biosystems Engineering, School of Agriculture, Shiraz University, Shiraz, Iran, Email: moradih@shirazu.ac.ir and Amin Mousavi Khaneghah, Department of Food Science and Nutrition, Faculty of Food Engineering, University of Campinas (UNICAMP), Rua Monteiro Lobato, 80. Caixa Postal: 6121.CEP: 13083-862, Campinas, São Paulo, Brazil, Email: mousavi@unicamp.br

Submitted: 6 November 2020. Accepted: 31 December 2020. Published: 29 January 2021. (C) 2021 Codon Publications

\section{OPEN ACCESS CC)(9) RESEARCH ARTICLE}

\section{Abstract}

The thin-layer drying kinetics of lemon verbena leaves were studied by using a solar cabinet dryer at air temperature (at three levels of 30,40 , and $50^{\circ} \mathrm{C}$ ), air velocity (at three levels of $2,2.5$, and $3 \mathrm{~m} / \mathrm{s}$ ), and mesh tray size $(3,6$, and $10 \mathrm{~mm}$ ). A completely randomized factorial design was used to analyze the effect of independent factors on drying time and essential oil yield. Results showed that all experiments have shorter drying time and higher essential oil content than the shade-drying method. Also, the best drying conditions that led to an optimal essential oil yield $(1.73 \mathrm{~mL} / \mathrm{g} \mathrm{DM})$ involved a lower temperature $\left(30^{\circ} \mathrm{C}\right)$ and velocity $(2 \mathrm{~m} / \mathrm{s})$ and a mesh size of $10 \mathrm{~mm}$. A good adaptation between the experimental and the predicted moisture content was observed, whereby the statistical criteria of $R^{2}$, root mean square error, and $\mathrm{k}^{2}$ were calculated as $0.99,0.08$, and 0.01 , respectively.

\section{Practical applications}

In the current study, the effect of different drying states such as air velocity and drying temperature was studied on the drying behaviors and essential oil contents of lemon verbena leaves. The obtained results can lead us to a suitable drying condition that can be used in the subsequent designation of systems. Also, a mathematical model for the prediction of the leaves' drying kinetics was constructed and evaluated, which could be approached in the drying systems.

Keywords: dimensionless model; essential oil content; mesh tray; monoterpene

\section{Introduction}

Lemon verbena (Aloysia citrodora) is a pharmaceutical plant. Its leaves have a powerful scent reminiscent of lemon, with several health benefits that help make lemon verbena have different applications in disease treatment (Harrison, 2012). In traditional medicine, this plant is used for treating many diseases such as indigestion, bloating, dizziness, and convulsion (Macfoy, 2013).
Lemon verbena leaves have an initial moisture content of $70.59 \%$ (wet basis). To prevent the leaves from deterioration, they should be dried. However, since they have a high amount of essential oil, suitable drying conditions are important. In relevant research, the influence of temperature was evaluated on lemon verbena's essential oil content by air drying. The temperature of the experiments was selected between 30 and $90^{\circ} \mathrm{C}$. The essential oil content decreased as the drying temperature 
increased, such that at temperatures of 30,45 , and $60^{\circ} \mathrm{C}$, about 16, 23, and $65 \%$ of the essential oil content was destroyed, respectively (Argyropoulos and Muller, 2014). In another study, the essential oil content of lemon verbena was extracted using three different drying methods: sun-drying, shade-drying, and oven drying (Agah and Najafian, 2012). The results revealed that the highest amounts of essential oil components (limonene, neral, and geranial) were obtained by the shade-drying method. However, the longest drying time was also observed by the shade-drying method.

Since the drying process uses a large amount of energy, the use of renewable energy resources for the drying of biological products has been investigated in different cases of research (EI-Sebaii and Shalaby, 2012; Eswara and Ramakrishnarao, 2013; Ezugwu, 2015; Jangam et al., 2011; Mujumdar \& Jangam, 2011; Vladut, 2010). Solar energy is a free, clean, and available resource of energy that is considered in different contexts as a primary source of energy for the drying process (Akbulut and Durmus, 2010; Akpinar, 2010; Amer et al., 2010; Bagheri et al., 2015; Bal et al., 2010; Zomorodian and Moradi, 2010).

Describing the drying behavior of products is important. Descriptions can be based on mathematical models. Mathematically modeling the thin-layer drying of materials is useful for further designs and applications of the dryers. Different modeling methods have been cited in the literature. These are mostly categorized into three groups: empirical, theoretical, and semi-empirical. Among them, theoretical models are less accurate due to simplifying assumptions in solving the issue's equations.

In contrast, semi-empirical models are more comfortable to obtain and can be employed in special conditions of drying used for predicting the moisture ratio. Also, empirical models can be achieved using regression, artificial neural networks, and dimensional analysis. Empirical models are obtained according to experimental results, and they usually lead to acceptable, accurate data that can assist in the modeling of a drying process aimed at agricultural products (Moradi et al., 2019). Dimensional analysis techniques are usually utilized to model sophisticated phenomena such as those involved in fluid mechanics. Dimensionless models have been used in some research cases for modeling the drying process (Esfahani et al., 2014; Moradi et al., 2016). Moradi et al. (2016) established a new dimensionless model for thin-layer drying of Aloe vera gel slices. In this regard, they found four dimensionless groups; one was dependent, and all the others were independent pi-terms. The final dimensionless Equation defined a relationship that described the dependent pi-term as a function of all independent pi-terms. Evaluations led to the obtained equation results and showed good agreement with the experimental results (Moradi et al., 2016).
The drying of a pharmaceutical plant must be done so that the essential oil content of the plant would continue to remain as much as possible. Based on our investigation, no previous study has been reported regarding the main and interaction effects of independent factors on the drying behavior and the quality of dried lemon verbena leaves. Therefore, the present work considers drying conditions in order to find their effects on the drying time and the remaining essential oil content of lemon verbena leaves. For this purpose, a solar cabinet dryer was employed at different mesh tray sizes, temperatures, and velocity levels. The dimensional analysis technique was utilized to construct a new dimensionless model for describing lemon verbena leaves' drying behavior.

\section{Materials and Methods}

\section{Sample preparation}

For each experiment, $25 \mathrm{~g}$ of fresh lemon verbena leaves were harvested from a farm field located at the agricultural school of Shiraz University. The leaves were then spread evenly on the mesh trays. The initial moisture content of the leaves was measured using an electric oven. To this end, fresh leaves were replaced in the electric oven at $70^{\circ} \mathrm{C}$ until a constant weight was reached. The leaves' average initial moisture content measured $70.93 \pm 0.1 \%$ (on a wet basis).

\section{Experimental setup}

\section{Solar dryer}

In order to obtain suitable drying conditions from the quantitative and qualitative aspects, this research was mainly allocated to investigating thin-layer drying of lemon verbena leaves in a solar dryer. For this purpose, a solar cabinet dryer was employed. It was manufactured in the Department of Biosystems Engineering at Shiraz University (Figure 1). The apparatus had a black solar collector (2) and a flat plate with $60 \times 150 \mathrm{~cm}^{2}$. An air channel was installed under the collector so that ambient air flowed through it using a centrifugal blower (1) $(\mathrm{SH}-2.5$, 260 watts) before entering a drying chamber (4). A thin layer of lemon verbena leaves (about $25 \mathrm{~g}$ ) was spread on a mesh tray (5) (with dimensions of $22 \times 33 \mathrm{~cm}^{2}$ ) inside the drying chamber. Usually, the collector's exhaust air enters the drying chamber and passes through the mesh tray to dry the lemon verbena leaves. Finally, moist air leaves the dryer through an exit duct (6) located in the dryer chamber's upper section. If the heat generated by the solar energy does not suffice, an auxiliary electrical heater (3) $(2 \mathrm{~kW})$ is installed at the inlet of the drying chamber. A digital thermostat was set so that the drying temperature can be adjusted at the desired values. 


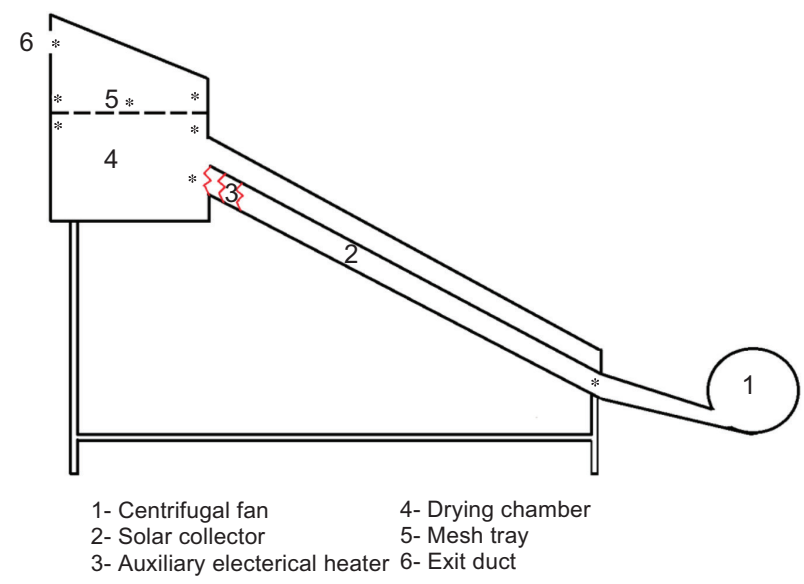

Figure 1. Schematic diagram of used solar dryer.

An electrical dimmer was used to change the blower's electric motor's rotational speed to obtain different airflow rates. The drying process continued until the drying sample's moisture content reached 9\% (wet basis). Also, the air temperature and humidity of drying were measured by 8 smart sensors (AM 2301, with an accuracy of $\pm 0.5^{\circ} \mathrm{C}$ and $0.3 \%$ of relative humidity). These sensors were installed on different parts of the dryer system (Figure 1, sensors have been illustrated with stars). Accordingly, two sensors were installed on the inlet and outlet of the solar collectors, respectively. Five sensors were installed on the drying chamber (two sensors before, two sensors after the mesh tray, and one sensor on the drying bed). Also, to measure outlet air temperature and humidity, a sensor was installed on the drying chamber's outlet. A data logger (Arduino) was used for collecting and recording the data generated by the sensors. The mesh tray containing the leaves was weighed every $10 \mathrm{~min}$ utes by a digital balance (A\&D, Japan, with an accuracy of $0.001 \mathrm{~g}$ ) to measure the drying sample's instantaneous moisture content.

\section{Shade drying}

Fresh lemon leaves were spread in a dark room with a temperature of $25 \pm 1^{\circ} \mathrm{C}$ with a ventilation fan. The relative humidity of the room changed between 20 and $25 \%$.

\section{Design of study}

A completely randomized factorial design was utilized for evaluating how the independent factors (air velocity, air temperature, and mesh tray size) affect the drying time and essential oil content of lemon verbena leaves. According to the literature, lemon verbena leaves dry in a temperature range of $30-50^{\circ} \mathrm{C}$ and a velocity range of 1-2 m/s (Infante et al., 2010; Soodmand-Moghaddam et al., 2020). Thus, three levels of air velocity (2, 2.5, and $3 \mathrm{~m} / \mathrm{s})$, drying temperature $\left(30,40\right.$, and $\left.50^{\circ} \mathrm{C}\right)$, and mesh tray size (with an equivalent diameter of 3,6 , and $10 \mathrm{~mm}$ ) were selected. The variance analysis and the mean comparison of values were based on the Duncan test $(\mathrm{P} \leq 0.01)$ using SPSS 16.

\section{Essential oil extraction}

Essential oil extraction was carried out by the hydro-distillation method. In this method, $15 \mathrm{~g}$ of dried lemon verbena was crushed at first and then hydro-distilled in a round bottom flask including $300 \mathrm{~mL}$ of deionized water for 2 hours by using an electromantle heater (EM2000/C, Electrothermal Engineering Ltd., UK, 335 W) equipped with Clevenger apparatus (Basti et al., 2007; Golmakani et al., 2017). The apparatus included a round bottom flask, condenser, essential oil collector, return section and electric heater. In this method, heat is transferred from the heater to the sample by conduction. After extraction, the obtained essential oil was dewatered and diluted with hexane. Then, gas chromatography-mass spectrometry (GC-MS) was employed for identifying the unknown components of essential oil. For this purpose, a gas chromatography (Agilent Technologies 7890A, USA) in conjunction with a mass spectrometer (Agilent Technologies 5975C, USA), operating at $70 \mathrm{eV}$ ionization energy, $0.5 \mathrm{~s} / \mathrm{scan}$, and a mass range of 35-400 amu, equipped with an HP-5MS capillary column (phenylmethyl siloxane, $30 \mathrm{~m}^{3} 0.25 \mathrm{~mm}$ ID; $0.25 \mathrm{~lm}$ film thickness), were used. Details of the GC-MS method are described in Golmakani et al. (2017).

The amount of the remaining essential oil was calculated using Equation (1):

$$
E=\frac{m_{e}}{m_{d}} \times 100
$$

where $\mathrm{E}$ is the essential oil content (\%), $\mathrm{m}_{\mathrm{e}}$ is the mass of extracted essential oil ( $\mathrm{g}$ ), and $\mathrm{m}_{\mathrm{d}}$ is the dry matter of lemon verbena $(\mathrm{g})$.

\section{Mathematical modeling}

Dimensional analysis is a useful and straightforward procedure that can be used for modeling sophisticated phenomena. In order to create a new model by using this method, the helpful variables in the drying process must be detected and combined to create dimensionless groups (pi terms). Based on the Buckingham Pi theorem, the number of dimensionless groups is equal to the number of total helpful parameters minus the number of prominent dimensions. Accordingly, the effective parameters in this research were $\mathrm{M}_{\mathrm{w}}, \mathrm{M}_{\mathrm{s}}, \mathrm{T}, \mathrm{T}_{\mathrm{a}}, \dot{\mathrm{m}}_{\mathrm{s}} \dot{\mathrm{m}}_{\mathrm{f}} \mathrm{d}$, $\mathrm{D}$, and Re. Where $\mathrm{M}_{\mathrm{w}}=$ mass of water in the leaves $(\mathrm{g})$, 
$\mathrm{M}_{\mathrm{s}}=$ mass of dry matter in the leaves $(\mathrm{g}), \mathrm{T}=$ drying air temperature $\left({ }^{\circ} \mathrm{C}\right), \mathrm{T}_{\mathrm{a}}=$ ambient air temperature $\left({ }^{\circ} \mathrm{C}\right), \dot{\mathrm{m}}_{\mathrm{s}}=$ mass of drying product on mesh tray per second $(\mathrm{kg} / \mathrm{s})$, $\dot{\mathrm{m}}_{\mathrm{f}}=$ mass flow rate of drying air $(\mathrm{kg} / \mathrm{s}), \mathrm{d}=$ equivalent diameter of mesh tray $(\mathrm{m}), \mathrm{D}=$ diameter of inlet air duct $(\mathrm{m})$, and $\mathrm{Re}=$ Reynolds number.

Among these nine parameters, there are four basic dimensions (meter, second, kilogram, and celsius). Therefore, according to the Buckingham Pi theorem, four independent dimensionless groups were formed between the remaining parameters by Equation (2):

$$
\begin{gathered}
\Pi_{1}=\frac{M_{w}}{\left(M_{w} /\left(M_{w}+M_{s}\right)\right)}, \quad \Pi_{2}=R e \\
\Pi_{3}=\frac{\dot{\mathrm{m}}_{\mathrm{s}}}{\dot{\mathrm{m}}_{\mathrm{f}}}, \quad \Pi_{4}=\frac{\mathrm{d}}{\mathrm{D}}, \quad \Pi_{5}=\frac{\mathrm{T}}{\mathrm{T}_{\mathrm{a}}}
\end{gathered}
$$

(Equation 2)

Since moisture content $\left(\left(M_{w}+M_{s}\right) / M_{s}\right)$ is a dimensionless factor that depends on different parameters, it can be considered a dependent group, while the others are independent pi-terms. According to dimensional analysis, an equation describing the relation between dependent and independent groups would be obtained (Equation 3) (Karparvarfard and Rahmanian-Koushkaki, 2015; Moradi et al., 2016).

$$
\Pi_{1}=\mathrm{F}\left(\Pi_{2}, \Pi_{3}, \Pi_{4}, \Pi_{5}\right)
$$

(Equation 3)

Equation (3) can be rewritten as a multiplication of separate functions of independent factors as Equation (4) (Eric et al., 2015).

$$
\Pi_{1}=C\left[F_{1}(\operatorname{Re}) \cdot F_{2}\left(\frac{\dot{\mathrm{m}}_{\mathrm{s}}}{\dot{\mathrm{m}}_{\mathrm{f}}}\right) \cdot \mathrm{F}_{3}\left(\frac{\mathrm{d}}{\mathrm{D}}\right) \cdot \mathrm{F}_{4}\left(\frac{\mathrm{T}}{\mathrm{T}_{\mathrm{a}}}\right)\right]^{\mathrm{n}} \text { (Equation 4) }
$$

where, $C$ and $n$ are constants and $F_{n}(n=(1,2,3$, and 4$)$ represent functions between dependent and each independent pi-term.

In order to obtain a linear equation, the logarithmic form of Equation (4) was written as Equation (5): (Karparvarfard and Rahmanian-Koushkaki, 2015)

$$
\begin{aligned}
& \log \left(\frac{M_{w}}{M_{w}+M_{s}}\right)=\log (C)+ \\
& n\left[\log \left[F_{1}(R e)\right]+\log \left[F_{2}\left(\frac{\dot{m}_{s}}{\dot{m}_{f}}\right)\right]+\log \left[F_{3}\left(\frac{d}{D}\right)\right]+\log \left[F_{4}\left(\frac{T}{T_{a}}\right)\right]\right]
\end{aligned}
$$

(Equation 5)

\section{Results and Discussion}

The effects of independent factors on dependent factors were evaluated within a completely randomized factorial design. The main effect and the double interaction effect of significant factors were highly significant on the drying time and the essential oil yield as dependent factors.

\section{Drying time}

The comparison of mean values about the main factors, according to Duncan's multiple range test, revealed that the mean value of the drying time for three velocity levels of $2,2.5$, and $3 \mathrm{~m} / \mathrm{s}$ were 250.26, 196.94, and $127.20 \mathrm{~min}$, respectively, indicating a decrease in drying time with the increase in air velocity. In other research, the effects of different air velocities and temperature levels were evaluated on the drying time. It was found that as air velocity increased, drying time reduced due to an increase in the evaporation rate (Putra and Ajiwiguna, 2017). Also, the mean drying time for three levels of mesh size of 3 , 6 , and $10 \mathrm{~mm}$ was calculated and were 201.93, 188.31, and 184.17, respectively, which shows that the drying time was shortened parallel to the increase in mesh size. This may be due to a larger orifice of a larger mesh tray, whereby a higher air volume can pass through it and cause the drying rate to increase, thereby shortening the drying time. The mean value of lemon verbena leaves' drying time was computed as $289.44,185.56$, and 99.407 min, respectively, at 30,40 , and $50^{\circ} \mathrm{C}$. Therefore, the drying time decreased as the temperature increased, consistent with previous research (Hasan et al., 2014; Jiang et al., 2017). There has been an indication in a previous report that thin layer drying characteristics of hybrid rice seeds show an increase in the drying rate as the drying temperature increases (Hasan et al., 2014). Since the interaction effect of double factors on drying time is significant, their mean comparison is carried out by SPSS 16 (Tables 1-3). From Table 1, it can be concluded that the shortest drying time occurred with the highest air velocity $(3 \mathrm{~m} / \mathrm{s})$, whereby more heat was transferred into the drying sample, and then more water was removed from the drying materials (Zomorodian and Moradi, 2010). This result is consistent with similar cases of research on air velocity and its effects on drying time (Putra and Ajiwiguna, 2017; Santacatalina et al., 2016). However, with an increase in the mesh tray size, the drying time decreased. Also, maximum drying time was observed by the least air velocity $(2 \mathrm{~m} / \mathrm{s})$ and the least mesh tray size $(3 \mathrm{~mm})$. The lower velocity may have caused the slower transfer of heat into the leaves, thereby removing lower amounts of water from the drying medium (Benitez, 2016).

Figure 2a shows the interaction effect of mesh size and velocity. The slope of variations in mesh size versus drying time was calculated. For the velocity of 2, 2.5, and 3 $\mathrm{m} / \mathrm{s}$, the slopes were calculated to be $2.86,2.54$, and 0.96 , respectively, whereby it can be concluded that a higher air velocity reduces the effect of mesh size on the drying 
Table 1. Mean comparison of the interaction effect of mesh size and velocity on drying time, essential oil yield, and oxygenated compounds.

\begin{tabular}{lcccc} 
Mesh size $(\mathrm{mm})$ & Velocity $(\mathrm{m} / \mathbf{s})$ & Drying time $(\mathrm{min})$ & Essential oil yield $(\%)$ & Oxygenated compound $(\mathrm{mg} / \mathrm{kg})$ \\
\hline 3 & 2 & $260.83 \mathrm{~A}$ & $1.33 \mathrm{~B}$ & $79.73 \mathrm{~B}$ \\
6 & 2 & $249.11 \mathrm{AB}$ & $1.31 \mathrm{~B}$ & $84.07 \mathrm{~A}$ \\
10 & 2 & $240.83 \mathrm{~B}$ & $1.38 \mathrm{~A}$ & $84.19 \mathrm{~A}$ \\
3 & 2.5 & $202.83 \mathrm{C}$ & $1.07 \mathrm{D}$ & $65.32 \mathrm{E}$ \\
6 & 2.5 & $187.00 \mathrm{D}$ & $1.07 \mathrm{D}$ & $67.56 \mathrm{D}$ \\
10 & 2.5 & $185.00 \mathrm{D}$ & $1.22 \mathrm{C}$ & $75.85 \mathrm{C}$ \\
3 & 3 & $130.83 \mathrm{E}$ & $0.80 \mathrm{G}$ & $48.76 \mathrm{H}$ \\
6 & 3 & $126.67 \mathrm{E}$ & $0.91 \mathrm{~F}$ & $56.32 \mathrm{G}$ \\
\hline
\end{tabular}

Table 2. Mean comparison of the interaction effect of mesh tray size and temperature on drying time, essential oil yield, and oxygenated compounds.

\begin{tabular}{|c|c|c|c|c|}
\hline Mesh size (mm) & Temperature $\left({ }^{\circ} \mathrm{C}\right)$ & Drying time (min) & Essential oil yield (\%) & Oxygenated compound (mg/kg) \\
\hline 3 & 30 & $328.33 \mathrm{~A}$ & $1.29 \mathrm{C}$ & $78.02 \mathrm{~B}$ \\
\hline 6 & 30 & $275 B$ & $1.38 \mathrm{~B}$ & $87.68 \mathrm{~A}$ \\
\hline 10 & 30 & $265 B$ & $1.44 \mathrm{~A}$ & $88.43 \mathrm{~A}$ \\
\hline 3 & 40 & $198.33 \mathrm{C}$ & $1.04 \mathrm{~F}$ & $62.61 \mathrm{E}$ \\
\hline 6 & 40 & $186.67 \mathrm{CD}$ & $1.09 \mathrm{E}$ & $70.01 \mathrm{D}$ \\
\hline 10 & 40 & $171.67 \mathrm{D}$ & $1.18 \mathrm{D}$ & $72.27 \mathrm{C}$ \\
\hline 3 & 50 & $105.78 \mathrm{E}$ & 0.821 & $53.18 \mathrm{G}$ \\
\hline 6 & 50 & $101.61 \mathrm{E}$ & $0.87 \mathrm{H}$ & $50.25 \mathrm{H}$ \\
\hline 10 & 50 & $90.833 \mathrm{E}$ & $0.96 \mathrm{G}$ & $60.52 \mathrm{~F}$ \\
\hline
\end{tabular}

Table 3. Mean comparison of the interaction effect of velocity and temperature on drying time, essential oil yield, and oxygenated compounds.

\begin{tabular}{lcccc} 
Velocity $(\mathrm{m} / \mathbf{s})$ & Temperature $\left({ }^{\circ} \mathrm{C}\right)$ & Drying time $(\mathrm{min})$ & Essential oil yield $(\%)$ & Oxygenated compounds (mg/kg) \\
\hline 2 & 30 & $405 \mathrm{~A}$ & $1.67 \mathrm{~A}$ & $104.94 \mathrm{~A}$ \\
2.5 & 30 & $301.67 \mathrm{~B}$ & $1.38 \mathrm{~B}$ & $84.03 \mathrm{~B}$ \\
3 & 30 & $161.67 \mathrm{C}$ & $1.07 \mathrm{DE}$ & $65.16 \mathrm{E}$ \\
2 & 40 & $227.5 \mathrm{D}$ & $1.31 \mathrm{C}$ & $79.22 \mathrm{C}$ \\
2.5 & 40 & $190.83 \mathrm{E}$ & $1.09 \mathrm{D}$ & $68.52 \mathrm{D}$ \\
3 & 40 & $138.33 \mathrm{~F}$ & $0.91 \mathrm{~F}$ & $57.15 \mathrm{~F}$ \\
2 & 50 & $118.28 \mathrm{G}$ & $1.05 \mathrm{E}$ & $63.82 \mathrm{E}$ \\
2.5 & 50 & $98.33 \mathrm{H}$ & $0.89 \mathrm{~F}$ & $56.18 \mathrm{~F}$ \\
3
\end{tabular}

time. This may be because, at a higher velocity, the airflow rate is sufficient to increase heat transfer into the drying sample and thus increase the removal rate of moisture from the drying materials. However, with a lower air velocity, an increase in mesh tray size would lead to a reduction in the resistance against the passing air, and, therefore, with a lower air velocity, the effect of mesh tray size on the drying time is increased.
Table 2 shows the comparison of mean values for the drying temperature and mesh tray size. The maximum drying time was obtained in the smallest mesh size $(3 \mathrm{~mm})$ and the lowest drying temperature $\left(30^{\circ} \mathrm{C}\right)$. The minimum drying time was also observed in mesh size of $10 \mathrm{~mm}$ and a temperature of $50^{\circ} \mathrm{C}$. In larger mesh sizes, resistance to air passage is reduced, thereby shortening the drying time. 
(a)

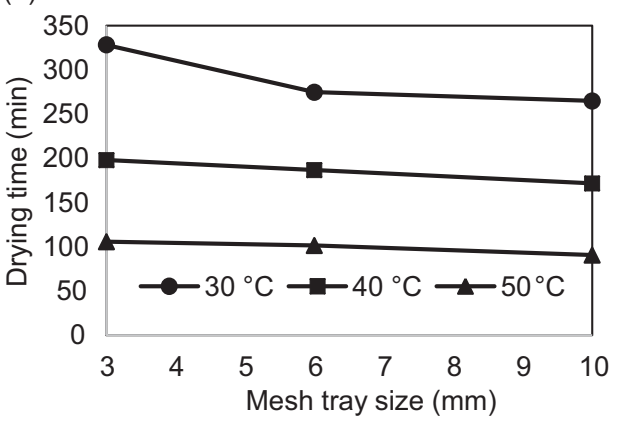

(b)

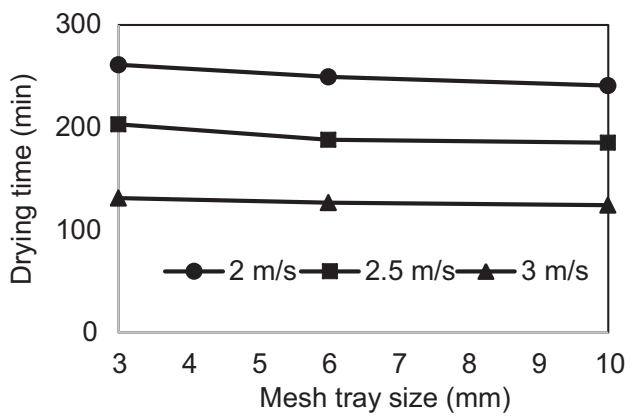

(c)

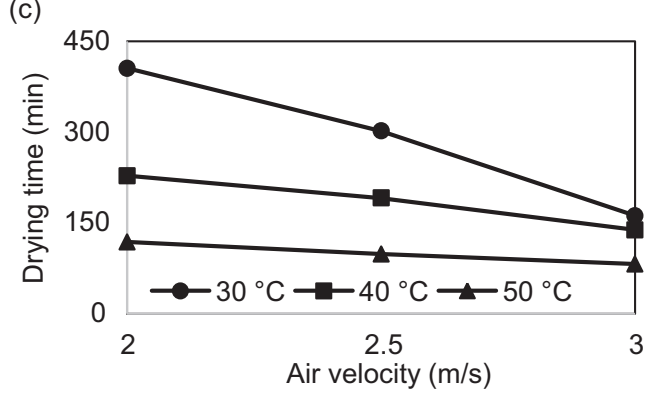

Figure 2. Double interaction effects on the drying time for (a) mesh tray size and air velocity, (b) air temperature and mesh tray size, (c) air temperature and velocity.

There were interactions between air temperature and mesh tray size (Figure 2b). The slopes of variations describing drying time versus mesh size at 30,40 , and $50^{\circ} \mathrm{C}$ were calculated as $9.05,3.81$, and 2.14 , respectively. Therefore, a stronger influence of mesh tray size was observed at lower drying temperatures. At higher temperatures, thermal energy is sufficient for dehydration as the increase in mesh size becomes less effective in dehydration in this case. Nonetheless, lower temperatures improved the efficiency of an increase in mesh tray size on the drying time.

Table 3 shows the comparison of mean values for the interaction effect of air velocity and temperature. Accordingly, the increase in air velocity and temperature can shorten the drying time. The maximum drying time was observed at the air velocity of $2 \mathrm{~m} / \mathrm{s}$ and the temperature of $30^{\circ} \mathrm{C}$ (405 min), whereas the minimum drying time was observed at the highest drying temperature of $50^{\circ} \mathrm{C}$ and the air velocity of $3 \mathrm{~m} / \mathrm{s}$. However, by increasing the drying temperature, the air velocity on the drying time was reduced (Figure 2c). Accordingly, the average slopes of drying time variations against the air velocity for temperatures of 30,40 , and $50^{\circ} \mathrm{C}$ were calculated as $-243.33,-89.17$, and -36.67 , respectively. In another research, three air temperature levels and three levels of air velocity were tested on the drying characteristics of cocoa beans. Results showed that the drying rate increased parallel to a rise in air temperature and velocity.
However, they reported a lower air velocity influence on the drying rate at higher drying temperatures (Ndukwu, 2009). In similar research, thin layer drying characteristics of Quercus were studied in response to exposure at different temperatures and velocity levels, whereby a greater influence of air velocity was observed at lower drying temperatures (Tahmasebi et al., 2011).

\section{Essential oil yield}

ANOVA results showed that independent factors' main and double interaction effects are significant on the essential oil yield. The comparison of mean values for the interaction effects was carried out as reported in Tables 1-3.

According to Table 1, the highest essential oil yield (1.38) was obtained by the lowest air velocity and by the mesh size of $10 \mathrm{~mm}$. However, the minimum essential oil yield (0.8) was observed due to the highest air velocity and by the mesh size of $3 \mathrm{~mm}$. In Figure 3a, the interaction effect of mesh size and air velocity shows that:

1. The increase in mesh size was parallel to the increase in oil yield at all levels of velocity. However, there appeared a sharper slope at higher air velocity levels that described the increase in oil yield versus mesh size. In other words, the effect of mesh size on the oil content was increased by higher levels of air velocity. 
2. In the same mesh sizes, with an increase in air velocity, the essential oil yield decreased. In a relevant study, the effect of air velocity on the essential oil content of lemongrass leaves was investigated. Their results revealed that the slope describing essential oil content versus velocity tended to plateau and that the essential oil content by three velocities of $0.8,1$, and $1.8 \mathrm{~m} / \mathrm{s}$ was measured as $0.808,0.797$, and $0.750 \%$, respectively (Rocha et al., 2012).

Table 3 compares mean values for the interaction effect of mesh size and temperature, showing that the largest mesh size obtained the maximum value of essential oil content (1.44) and at the lowest air temperature. However, the minimum value of yield (0.82) was obtained at the maximum air temperature and by the smallest mesh size.

Figure $3 \mathrm{~b}$ shows the interaction effect of mesh size and air temperature on essential oil content.

1. At a constant temperature, by increasing the mesh size, the oil yield increased.

2. In each mesh size, the essential oil content decreased by increasing the temperature, which is in good agreement with previous research findings (Ebadi et al., 2015; Infante et al., 2010). In other relevant research, the drying of lemon verbena leaves by the oven method at different temperatures led to different quantities of the extracted essential oil, showing a downward trend in the quantity of essential oil with an increase in drying temperature. More specifically, the essential oil content became 98.2, 98.2, and $97.8 \%$ when the drying was performed at 40, 50, and $60^{\circ} \mathrm{C}$, respectively (Ebadi et al., 2015).

3. The slopes of increase in the oil yield versus mesh size at 30,40 , and $50^{\circ} \mathrm{C}$ were calculated as 0.022 , 0.019 , and 0.019 , respectively, which show that the mesh size has more influence on the oil content at $30^{\circ} \mathrm{C}$ compared with the other temperatures.

Table 3 illustrates the mean comparison of interaction effects between temperature and velocity on essential oil content. Accordingly, the highest essential oil yield (1.667) was observed at the lowest velocity and temperature, whereas the highest velocity and temperature observed the least oil content (0.713). In similar studies, the essential oil content decreased as the drying temperature, and velocity increased (Ebadi et al., 2015; Rocha et al., 2012).

Figure 3c shows the interaction effect of temperature and velocity on essential oil content.

1. In each temperature level, by increasing the air velocity, oil content decreased, which is consistent with research performed by Rocha et al. (2012).

2. The slopes of oil content variations versus velocity at 30,40 , and $50^{\circ} \mathrm{C}$ were $0.60,0.40$, and 0.33 , respectively, which shows more influence of velocity on essential oil content at lower temperatures. (a)

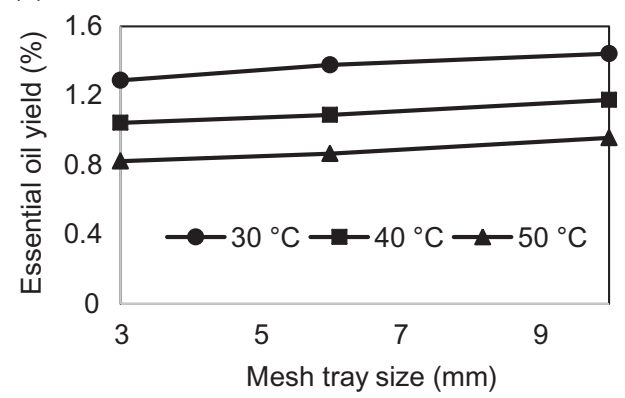

(b)

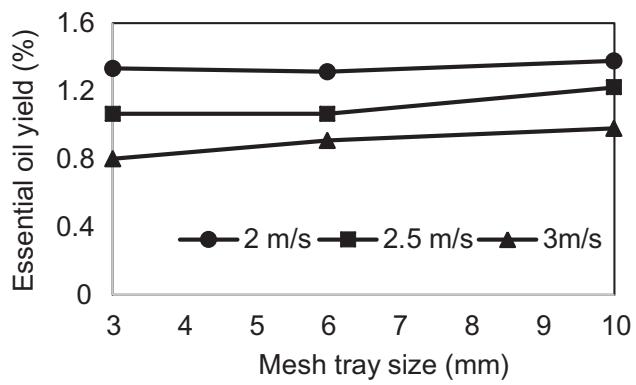

(c)

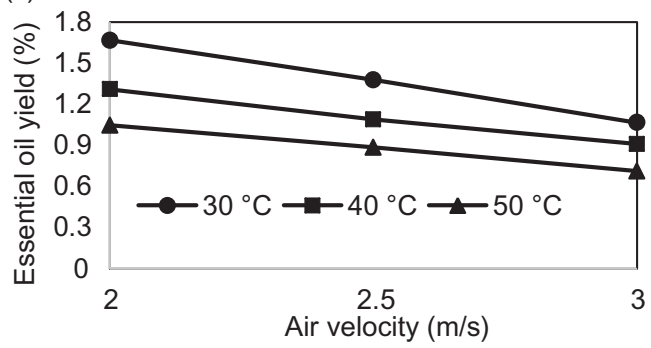

Figure 3. Double interaction effects on drying time for (a) mesh tray size and air velocity, (b) air temperature and mesh tray size, (c) air temperature and velocity. 
3. At each velocity level, the essential oil content decreased as the temperature increased. In another study, lemon verbena leaves were dried at 40,50, and $60^{\circ} \mathrm{C}$, and the results showed higher essential oil at lower temperatures (Ebadi et al., 2015).

\section{Essential oil composition}

Since the effect of different drying conditions on oxygenated compounds is highly significant, the calculations led to the mean comparison of interaction effects between mesh size and velocity on oxygenated components (Table 1 ). The mean values of oxygenated compounds in response to the three velocities of $2,2.5$, and $3 \mathrm{~m} / \mathrm{s}$ were $82.66,69.58$, and $55.42 \mathrm{mg} / \mathrm{kg}$, respectively. Also, the amount of oxygenated compounds resulting from the three mesh sizes of 3,6 , and $10 \mathrm{~mm}$ were 64.60, 69.31, and $73.74 \mathrm{mg} / \mathrm{kg}$, respectively. Therefore, oxygenated components increased parallel to the increase in mesh size and the decrease in drying velocity. Accordingly, the highest amount of oxygenated compound $(84.19 \mathrm{mg} / \mathrm{kg}$ ) was obtained by the lowest drying velocity $(2 \mathrm{~m} / \mathrm{s})$ and by the largest mesh size $(10 \mathrm{~mm})$.

The mean comparison of interaction effects between mesh tray size and drying temperature on the yield of oxygenated components are illustrated in Table 3. Accordingly, the mean values of oxygenated components obtained at 30,40 , and $50^{\circ} \mathrm{C}$ were $84.71,68.29$, and 54.65 $\mathrm{mg} / \mathrm{kg}$, respectively. Therefore, the amount of oxygenated compounds increased as mesh size increased and temperature decreased, such that the highest oxygenated compound yield of $88.43 \mathrm{mg} / \mathrm{kg}$ was observed in the mesh size of $10 \mathrm{~mm}$ and at $30^{\circ} \mathrm{C}$.

Table 3 shows the mean comparison of interaction effects between temperature and velocity on the yield of oxygenated compounds. The average yields of oxygenated components obtained by the velocities of $2,2.5$, and $3 \mathrm{~m} / \mathrm{s}$ were $82.66,69.58$, and $55.42 \mathrm{mg} / \mathrm{kg}$, respectively. These values indicate that the yield of oxygenated components increases as the drying air velocity is reduced. In this manner, the highest oxygenated yield $(104.94 \mathrm{mg} / \mathrm{kg})$ was obtained by the velocity of $2 \mathrm{~m} / \mathrm{s}$ and at $30^{\circ} \mathrm{C}$.

The compounds of essential oil that were identified in shade-dried lemon verbena are shown in Table 4. Accordingly, 26 different components were recognized in the essential oil of shade-dried lemon verbena. The most abundant of these components were limonene, geranial, neral, and cineole, with $18.29,26.78,16.28$, and 5.66\%, respectively. In another study, different compounds of lemon verbena were extracted by using different methods of hydro-distilled, microwave-assisted hydro-distilled, and solvent-free microwave extraction, whereby it was revealed that neral and geranial were the most abundant components in the essential oil of lemon verbena, regardless of the extraction method in use (Golmakani et al., 2017).

Table 5 shows the percentage of significant compounds of limonene, geranial, neral, and cineole for different drying conditions. The maximum amount of limonene (19.74\%) belonged to an experiment with a velocity of $2.5 \mathrm{~m} / \mathrm{s}$, a temperature of $50^{\circ} \mathrm{C}$, and a mesh size of $6 \mathrm{~mm}$. The experiment with a velocity of $2 \mathrm{~m} / \mathrm{s}$, a temperature of $50^{\circ} \mathrm{C}$, and a mesh size of $3 \mathrm{~mm}$ showed the highest yield of geranial. Neral had a maximum amount of $35.04 \%$ in an experiment with a velocity of $2 \mathrm{~m} / \mathrm{s}$, a temperature of $30^{\circ} \mathrm{C}$, and a mesh size of $10 \mathrm{~mm}$. Cineole had a maximum yield of $7.78 \%$ in an experiment with a velocity of $2.5 \mathrm{~m} / \mathrm{s}$, a temperature of $30^{\circ} \mathrm{C}$, and a mesh size of $10 \mathrm{~mm}$. The amounts of oxygenated monoterpenes increased as the drying temperature and velocity decreased. The highest value of oxygenated monoterpenes (83.33) was obtained at the lowest drying air temperature $\left(30^{\circ} \mathrm{C}\right)$, air velocity $(2 \mathrm{~m} / \mathrm{s})$, and mesh size of $6 \mathrm{~mm}$. However, the lowest value of oxygenated monoterpenes (31.57) was observed in the shade-drying treatment. In total, oxygenated monoterpenes decreased as the drying temperature, and velocity increased. Oxygenated monoterpenes showed an unclear relationship with the mesh size of trays.

The analysis of oxygenated sesquiterpenes revealed that their content increased by reducing the velocity and temperature. Thus, the maximum quantity of oxygenated sesquiterpenes (28.89) was achieved at a temperature of $30^{\circ} \mathrm{C}$, the velocity of $2 \mathrm{~m} / \mathrm{s}$, and mesh size of $10 \mathrm{~mm}$. However, the lowest quantity of oxygenated sesquiterpenes (9.23) was observed at a temperature of $50^{\circ} \mathrm{C}$, the velocity of $3 \mathrm{~m} / \mathrm{s}$, and mesh size of $3 \mathrm{~mm}$. In another research, the changes in essential oil content and the composition of Thymus daenensis under different drying conditions showed that as the drying temperature increased in the oven, the essential oil content decreased. Also, decreases in cineole and limonene were reported by increasing the drying temperature (Dehghani Mashkani et al., 2018).

Therefore, our results on the quality assessment of lemon verbena essential oil revealed that all experimental treatments in the thin-layer drying method show higher essential oil yield and chemical composition than the shade-drying method. Our results are also in good agreement with the findings of other researchers who reported the effects of different drying operations on essential oil content and composition. Our findings showed that lower drying temperatures and velocities, along with a larger mesh size, cause higher essential oil yield and composition than shade drying. However, another research proved otherwise by 
Table 4. Essential oil compositions of shade-dried lemon verbena.

\begin{tabular}{|c|c|c|c|c|c|c|}
\hline No. & RT (min) & Common name & $\begin{array}{l}\text { Molecular } \\
\text { formula }\end{array}$ & $\begin{array}{c}\text { Molar mass } \\
\text { (g/mole) }\end{array}$ & Classification & Percentage \\
\hline 1 & 3.50 & $\alpha$-Pinene & $\mathrm{C}_{10} \mathrm{H}_{16}$ & 136.23 & Monoterpene hydrocarbon & 0.995 \\
\hline 2 & 4.78 & $\beta$-Phellandrene & $\mathrm{C}_{10} \mathrm{H}_{16}$ & 136.23 & Monoterpene hydrocarbon & 2.13 \\
\hline 3 & 5.79 & D-Limonene & $\mathrm{C}_{10} \mathrm{H}_{16}$ & 136.24 & Monoterpene hydrocarbon & 18.29 \\
\hline 4 & 6.52 & trans-beta-Ocimene & $\mathrm{C}_{10} \mathrm{H}_{16}$ & 136.24 & Monoterpene hydrocarbon & 0.47 \\
\hline 5 & 6.85 & 1, 8-Cineole & $\mathrm{C}_{10} \mathrm{H}_{18} \mathrm{O}$ & 154.24 & Oxygenated monoterpene & 5.66 \\
\hline 6 & 10.30 & Trans sabinene hydrate & $\mathrm{C}_{10} \mathrm{H}_{18} \mathrm{O}$ & 154.25 & Oxygenated monoterpene & 0.55 \\
\hline 7 & 11.09 & L-linalool & $\mathrm{C}_{10} \mathrm{H}_{18} \mathrm{O}$ & 154.25 & Oxygenated monoterpene & 0.56 \\
\hline 8 & 11.33 & Cis-limonene oxide & $\mathrm{C}_{10} \mathrm{H}_{16} \mathrm{O}$ & 152.12 & Oxygenated monoterpene & 0.35 \\
\hline 9 & 12.27 & Beta Citronellal & $\mathrm{C}_{10} \mathrm{H}_{18} \mathrm{O}$ & 154.14 & Oxygenated monoterpene & 0.14 \\
\hline 10 & 13.18 & Photocitral & $\mathrm{C}_{10} \mathrm{H}_{16} \mathrm{O}$ & 152.12 & Oxygenated monoterpene & 1.5 \\
\hline 11 & 13.75 & Camphorquinone & $\mathrm{C}_{10} \mathrm{H}_{18} \mathrm{O}$ & 166.1 & Oxygenated monoterpene & 2.00 \\
\hline 12 & 14.60 & Alpha Terpineol & $\mathrm{C}_{10} \mathrm{H}_{18} \mathrm{O}$ & 154.25 & Oxygenated monoterpene & 1.26 \\
\hline 13 & 15.73 & Trans-caryophyllene & $\mathrm{C}_{15} \mathrm{H}_{24}$ & 204.36 & Sesquiterpene hydrocarbon & 1.90 \\
\hline 14 & 16.47 & Aromadendrene & $\mathrm{C}_{15} \mathrm{H}_{24}$ & 204.35 & Sesquiterpene hydrocarbon & 0.8 \\
\hline 15 & 16.86 & Neral & $\mathrm{C}_{10} \mathrm{H}_{18} \mathrm{O}$ & 152.23 & Oxygenated monoterpene & 16.28 \\
\hline 16 & 17.40 & Neryl acetate & $\mathrm{C}_{12} \mathrm{H}_{20} \mathrm{O}_{2}$ & 196.15 & Oxygenated monoterpene & 1.17 \\
\hline 17 & 17.83 & Geranial & $\mathrm{C}_{10} \mathrm{H}_{16} \mathrm{O}$ & 152.23 & Oxygenated monoterpene & 26.78 \\
\hline 18 & 19.05 & Geranyl acetate & $\mathrm{C}_{12} \mathrm{H}_{20} \mathrm{O}_{2}$ & 196.29 & Oxygenated monoterpene & 0.38 \\
\hline 19 & 21.27 & Nerolidol & $\mathrm{C}_{15} \mathrm{H}_{26} \mathrm{O}$ & 222.37 & Oxygenated Sesquiterpene & 0.14 \\
\hline 20 & 21.27 & Methyl eugenol & $\mathrm{C}_{11} \mathrm{H}_{14} \mathrm{O}_{2}$ & 178.1 & Oxygenated monoterpene & 0.14 \\
\hline 21 & 21.6 & Eugenol & $\mathrm{C}_{10} \mathrm{H}_{12} \mathrm{O}_{2}$ & 164.08 & Oxygenated monoterpene & 0.14 \\
\hline 22 & 23.89 & Spathulenol & $\mathrm{C}_{15} \mathrm{H}_{24} \mathrm{O}$ & 220.35 & Oxygenated Sesquiterpene & 3.41 \\
\hline 23 & 24.45 & Delta.-cadinene & $\mathrm{C}_{15} \mathrm{H}_{24}$ & 204.35 & Sesquiterpene hydrocarbon & 2.01 \\
\hline 24 & 25.19 & Isopathulenol & $\mathrm{C}_{15} \mathrm{H}_{24} \mathrm{O}$ & 220.18 & Oxygenated Sesquiterpene & 0.5 \\
\hline 25 & 26.21 & Alloaromadendrene oxide & $\mathrm{C}_{15} \mathrm{H}_{24} \mathrm{O}$ & 220.18 & Oxygenated Sesquiterpene & 0.27 \\
\hline 26 & 26.41 & Isoaromadendrene epoxide & $\mathrm{C}_{15} \mathrm{H}_{24} \mathrm{O}$ & 220.18 & Oxygenated Sesquiterpene & 0.38 \\
\hline
\end{tabular}

examining different drying methods of lemon verbena, including sun drying, shade drying, and oven drying at a temperature of $60^{\circ} \mathrm{C}$, whereby lower essential oil content and chemical composition were obtained compared to when the shade drying method was used (Agah and Najafian, 2012). In similar research, the drying of lemon verbena leaves was carried out at a temperature range of $30-90^{\circ} \mathrm{C}$, by which lower amounts of essential oil were obtained at the lower temperature levels. More specifically, the process of drying at 30 and $45^{\circ} \mathrm{C}$ caused 16 and $23 \%$ of the essential oil content to be removed, respectively. Meanwhile, higher temperature levels caused about $65 \%$ of the essential oil content to be removed (Argyropoulos and Muller, 2014).

\section{Mathematical modeling}

In order to find the $\log \left(\mathrm{F}_{1}\right)$ to $\log \left(\mathrm{F}_{4}\right)$, first, we plotted the $\log \left(M_{w} /\left(M_{w}+M_{s}\right)\right)$ against the $\log \left(\dot{m}_{s} / \dot{m}_{\mathrm{f}}\right)$ for each replication of the experiment (Figure 4). Then, the points with the same values of $\log (\mathrm{Re})$ were recognized and connected to create different parallel lines. The vertical distance of each line from the origin was calculated and considered as the change rate of Log $\left(\mathrm{F}_{1}\right.$ (Re)) (Karparvarfard and Rahmanian Kushkaki, 2015). Therefore, the values of $\log (\mathrm{F} 1(\mathrm{Re}))$ were plotted against

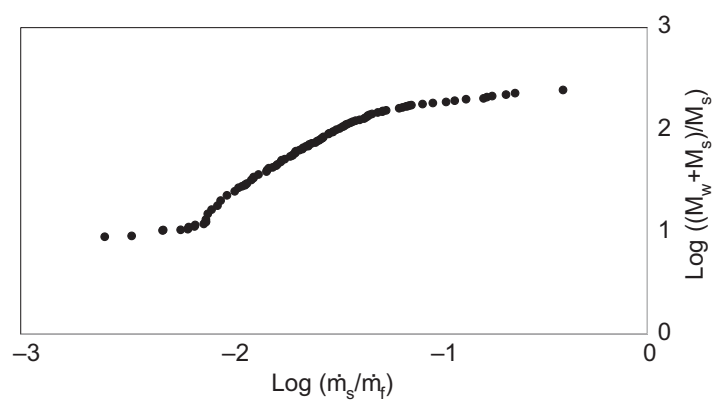

Figure 4. Variations of $\log \left(\dot{m}_{s} / \dot{m}_{f}\right)$ versus $\log \left(\left(M_{w}+M_{s}\right) / M_{s}\right)$. 


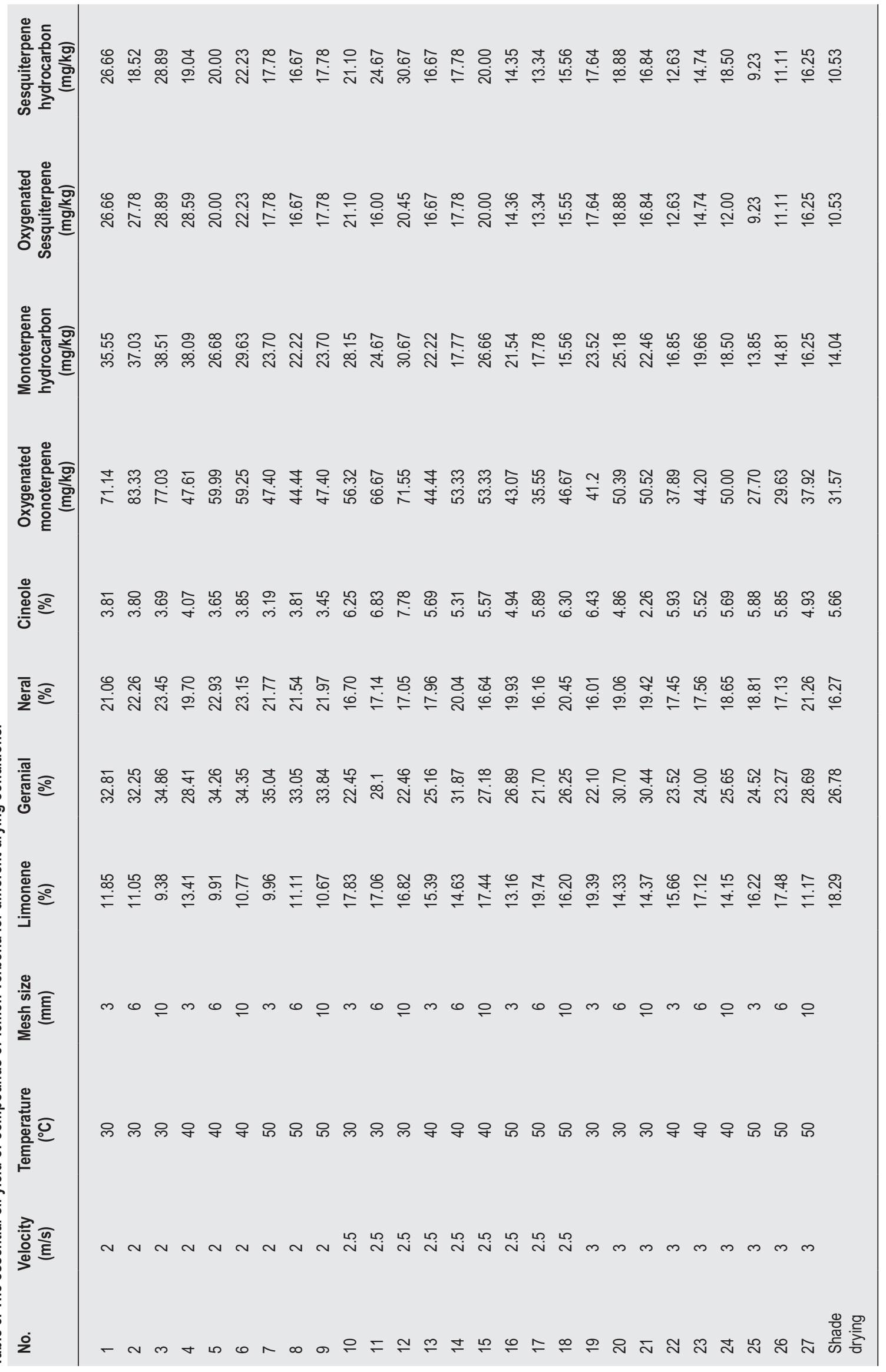


the amounts of $\log (\mathrm{Re})$, as shown in Figure 5, and then the best-fitted Equation was obtained. Figure 5 shows the relation between $\log (\mathrm{Re})$ and $\log (\mathrm{F} 1(\mathrm{Re}))$ for the first replication of the experimental data. The process was replicated for three replications of experimental data, and an average equation, called Equation (6), was obtained:

$$
\operatorname{LogF}_{1}(\operatorname{Re})=-6.052 \log (\operatorname{Re}) \quad(\text { Equation 6) }
$$

which can be rewritten as Equation (7):

$$
F_{1}(\operatorname{Re})=\operatorname{Re}^{-6.052}
$$

(Equation 7)

In order to find $\log \mathrm{F}_{2}\left(\dot{\mathrm{m}}_{\mathrm{s}} / \dot{\mathrm{m}}_{\mathrm{f}}\right)$, the values of $\log \mathrm{F}_{1}(\mathrm{Re})$ were subtracted from the corresponding values of $\mathrm{Log}$ $\left(\mathrm{M}_{\mathrm{w}} /\left(\mathrm{M}_{\mathrm{w}}+\mathrm{M}_{\mathrm{s}}\right)\right)$ as (Equation 8$)$ :

$\log \left(\frac{M_{w}}{M_{w}+M_{s}}\right)-\log F_{1}(R e)=\log F_{2}\left(\frac{\dot{m}_{s}}{\dot{m}_{f}}\right)$

The obtained values of $\log \mathrm{F}_{2}\left(\dot{\mathrm{m}}_{\mathrm{s}} / \dot{\mathrm{m}}_{\mathrm{f}}\right)$ were plotted versus the values of $\log \left(\dot{\mathrm{m}}_{\mathrm{s}} / \dot{\mathrm{m}}_{\mathrm{f}}\right)$ and then the best-fitted Equation was calculated using the regression analysis. Figure 6 illustrates the relationship between $\log \mathrm{F}_{2}$ $\left(\dot{\mathrm{m}}_{\mathrm{s}} / \dot{\mathrm{m}}_{\mathrm{f}}\right)$ and $\log \left(\dot{\mathrm{m}}_{\mathrm{s}} / \dot{\mathrm{m}}_{\mathrm{f}}\right)$ according to the first replication of the experimental data. Therefore, three best-fitted equations were computed from the three replications. These were averaged, which led to Equation (9).

$$
\log \mathrm{F}_{2}\left(\frac{\dot{\mathrm{m}}_{\mathrm{s}}}{\dot{\mathrm{m}}_{\mathrm{f}}}\right)=1.81 \log \left(\frac{\dot{\mathrm{m}}_{\mathrm{s}}}{\dot{\mathrm{m}}_{\mathrm{f}}}\right) \quad(\text { Equation 9) }
$$

Equation (8) can be rewritten as Equation (10):

$$
\mathrm{F}_{2}\left(\frac{\dot{\mathrm{m}}_{\mathrm{s}}}{\dot{\mathrm{m}}_{\mathrm{f}}}\right)=\left(\frac{\dot{\mathrm{m}}_{\mathrm{s}}}{\dot{\mathrm{m}}_{\mathrm{f}}}\right)^{1.81} \quad \text { (Equation 10) }
$$

To obtain $\log \mathrm{F}_{3}(\mathrm{~d} / \mathrm{D})$, (Equation 11) was used:

$$
\log \left(\frac{M_{w}}{M_{w}+M_{s}}\right)-\log F_{1}(R e)-\log F_{2}\left(\frac{\dot{m}_{s}}{\dot{m}_{f}}\right)=\log F_{3}\left(\frac{d}{D}\right)
$$

(Equation 11)

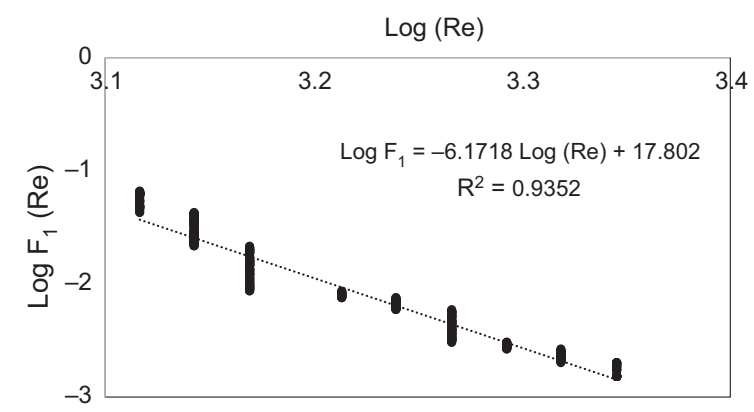

Figure 5. Variations of $\log F_{1}(R e)$ versus $\log (R e)$ for the first replication.

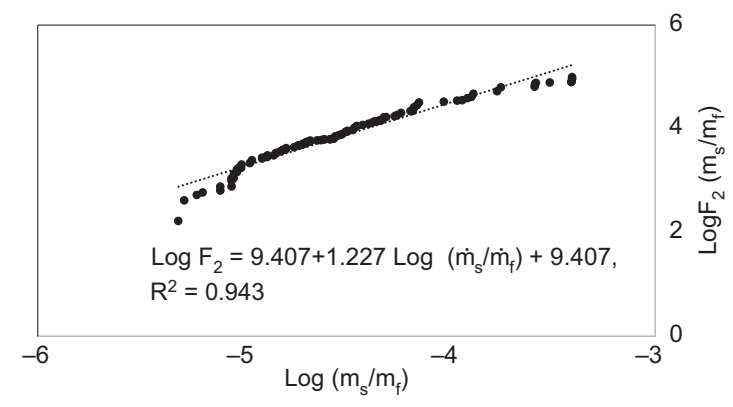

Figure 6. Variations of $\log \left(\dot{m}_{s} / \dot{m}_{f}\right)$ versus $\log F_{2}\left(\dot{m}_{s} / \dot{m}_{f}\right)$ for the first replication.

The obtained values of Equation (11) were plotted versus the values of $\log (\mathrm{d} / \mathrm{D})$ and then the best-fitted Equation was obtained. Three best-fitted equations were derived from three replications of experimental data. For instance, Figure 7 shows the best-fitted Equation for the first replication. Equation (12) presents the average values of the three best-fitted equations:

$$
\log _{3}\left(\frac{d}{D}\right)=2.362 \log \left(\frac{d}{D}\right) \text { (Equation 12) }
$$

where Equation (12) can be written as Equation (13):

$$
F_{3}\left(\frac{d}{D}\right)=\left(\frac{d}{D}\right)^{2.362}
$$

In the following, for the sake of obtaining $\mathrm{F}_{4}\left(\mathrm{~T} / \mathrm{T}_{\mathrm{a}}\right)$, Equation (14) was used:

$$
\begin{aligned}
& \log \left(\frac{M_{w}}{M_{w}+M_{s}}\right)-\log F_{1}(R e)-\log F_{2}\left(\frac{\dot{m}_{s}}{\dot{m}_{f}}\right)-\log F_{3}\left(\frac{d}{D}\right) \\
& =\log _{4}\left(\frac{T}{T_{a}}\right)
\end{aligned}
$$

(Equation 14)

Then, as done before, the $\log \mathrm{F}_{4}\left(\mathrm{~T} / \mathrm{T}_{\mathrm{a}}\right)$ versus $\log \left(\mathrm{T} / \mathrm{T}_{\mathrm{a}}\right)$ was plotted, and the best-fitted Equation was obtained for each replication of the experimental data. Figure 8 shows the relationship between $\log \mathrm{F}_{4}\left(\mathrm{~T} / \mathrm{T}_{\mathrm{a}}\right)$ versus $\mathrm{Log}$

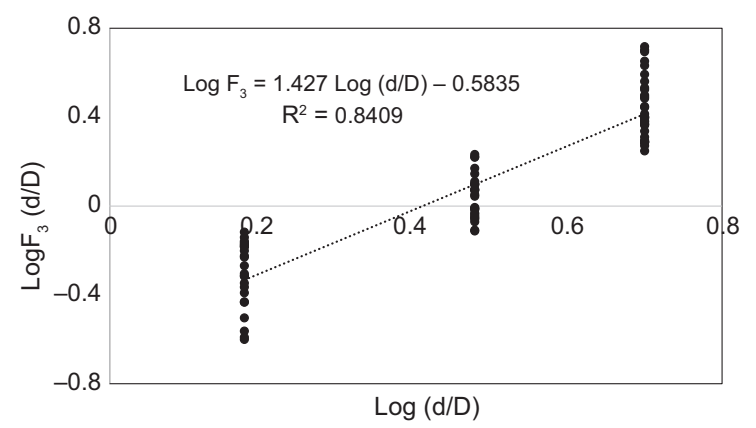

Figure 7. Variations of $\log (d / D)$ versus $\log F_{3}(d / D)$ for the first replication. 
$\left(\mathrm{T} / \mathrm{T}_{\mathrm{a}}\right)$, which is provided from the first replication of the experimental data. Equation (15) is an average value of three equations.

$$
\log _{4}\left(\frac{T}{T_{a}}\right)=5.226 \log \left(\frac{T}{T_{a}}\right)(\text { Equation 15) }
$$

Which Equation (15) can be rewritten as Equation (16):

$$
\mathrm{F}_{3}\left(\frac{\mathrm{T}}{\mathrm{T}_{\mathrm{a}}}\right)=\left(\frac{\mathrm{T}}{\mathrm{T}_{\mathrm{a}}}\right)^{5.226}
$$

(Equation 16)

In order to acquire a generalized dimensionless relation, Equations (7), (10), (13), and (16) were incorporated into Equation (3). Finally, Equation (17) was obtained for describing the dependent pi-term as a function of independent pi-terms.

$$
\frac{M_{w}}{M_{w}+M_{s}}=C\left[(R e)^{-6.052} \times\left(\frac{\dot{m}_{s}}{\dot{m}_{f}}\right)^{1.81} \times\left(\frac{d}{D}\right)^{2.362} \times\left(\frac{T}{T_{a}}\right)^{5.226}\right]^{n}
$$

(Equation 17)

In order to obtain "C" and "n", Equation (16) was rewritten as Equation (18):

$$
\begin{aligned}
\log (M C)= & \log (C) \\
& +n \log \left[\mathrm{F}_{1}(\operatorname{Re}) \times \mathrm{F}_{2}\left(\frac{\dot{\mathrm{m}}_{\mathrm{s}}}{\dot{\mathrm{m}}_{\mathrm{f}}}\right) \times \mathrm{F}_{3}\left(\frac{\mathrm{d}}{\mathrm{D}}\right) \times \mathrm{F}_{4}\left(\frac{\mathrm{T}}{\mathrm{T}_{\mathrm{a}}}\right)\right]
\end{aligned}
$$

(Equation 18)

In Equation (18), the values inside the bracelet are already known; hence, if the logarithmic value of $M_{w} /\left(M_{w}+M_{s}\right)$ is plotted versus the logarithmic value of the inner bracelet (Figure 9), then " $\mathrm{n}$ " and " $\mathrm{C}$ " can be obtained from its slope and interception. Therefore, the final dimensionless Equation would turn out as Equation (19):

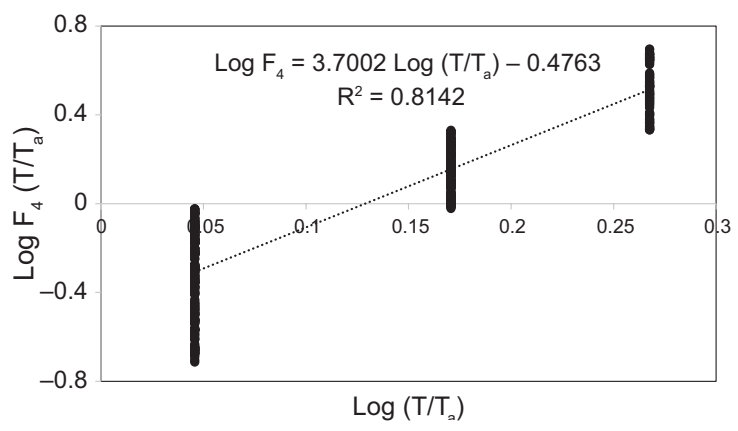

Figure 8. Variations of $\log \left(T / T_{a}\right)$ versus $\log F_{4}\left(T / T_{a}\right)$ for the first replication.

$$
\begin{aligned}
& \frac{M_{w}}{M_{w}+M_{s}} \\
& \quad=10^{2.11}\left[(\operatorname{Re})^{-6.052} \times\left(\frac{\dot{\mathrm{m}}_{\mathrm{s}}}{\dot{\mathrm{m}}_{\mathrm{f}}}\right)^{1.81} \times\left(\frac{\mathrm{d}}{\mathrm{D}}\right)^{2.362} \times\left(\frac{\mathrm{T}}{\mathrm{T}_{\mathrm{a}}}\right)^{5.226}\right]^{0.1008}
\end{aligned}
$$

(Equation 19)

It should be noted that nearly $80 \%$ of the experimental data were used for establishing the dimensionless model and $20 \%$ of the remaining data were employed to evaluate the model. The obtained model could be used in the following ranges of the operating conditions:

1. Range of drying temperature: $30^{\circ} \mathrm{C} \leq \mathrm{T} \leq 50^{\circ} \mathrm{C}$

2. Range of air velocity: $2 \mathrm{~m} / \mathrm{s} \leq \mathrm{V} \leq 3 \mathrm{~m} / \mathrm{s}$

However, lemon verbena's moisture content must be in the range of $9 \% \leq \mathrm{MC}$ (wet basis) $\leq 70.93 \%$.

\section{Model validation}

In order to recommend a newly constructed model, the proposed model must be validated. Validating is an essential part of the mathematical modeling process, providing the required confidence (Ho et al., 2013; Perrot et al., 2011; Trystram, 2012). Therefore, some statistical criteria, such as coefficient of determination $\left(R^{2}\right)$, root mean square error (RMSE) and Mean Relative Deviation (MRD), can be gauged (Morton et al., 2018). In this regard, the dimensionless model was established using $80 \%$ of the experimental data, and $20 \%$ of the remaining data were selected afterward using the experimental setup. Their moisture content was determined and compared with the calculated values by the obtained dimensionless model. A good agreement was observed; $\mathrm{R}^{2}$, RMSE, and $\mathrm{k}^{2}$ of the comparison were $0.99,0.079$, and 0.01 , respectively. Figure 10 shows the predicted moisture content of lemon verbena leaves versus the measured values of moisture content.

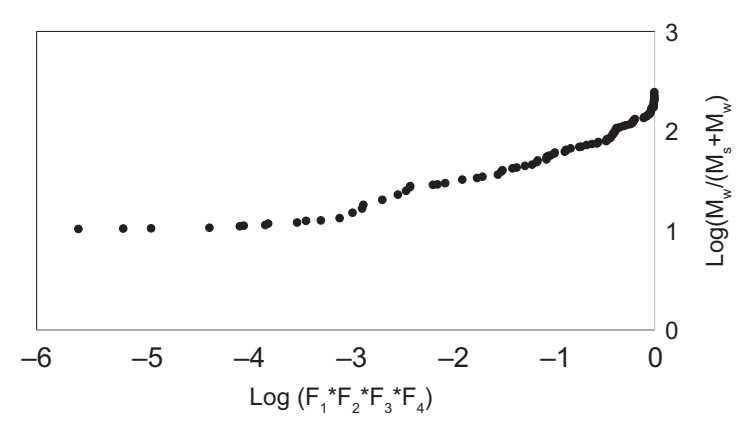

Figure 9. $\log \left(M w /(M s+M w)\right.$ versus $\log \left(F_{1} F_{2} F_{3} F_{4}\right)$. 


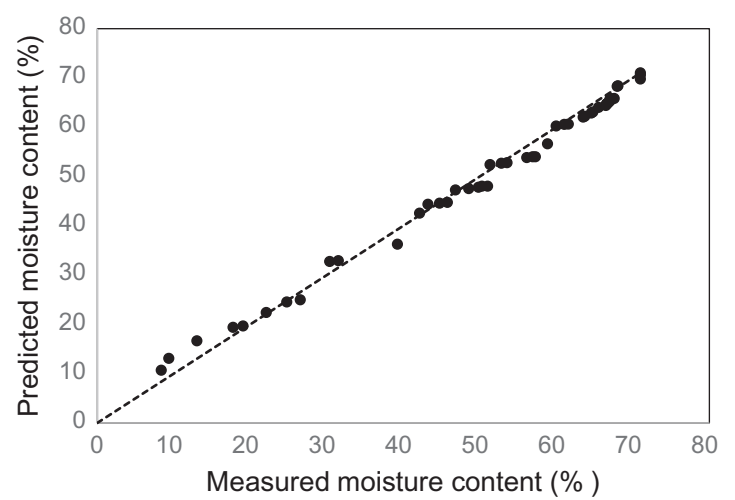

Figure 10. Predicted moisture content of lemon verbena leaves versus measured moisture content (wet basis).

In another research, a dimensional analysis technique was utilized to establish two dimensionless models for describing the drying behaviors of aloe vera gel slices in a hot air drying and Osmo-convective drying method (Moradi et al., 2016). In the constructed models, three independent groups were characterized and used to describe aloe vera gel slices' instantaneous moisture content. Models' validation showed a coefficient of determination of osmo-convective and convective models are 0.99 and 0.98 , respectively. Also, in another research, a new dimensionless model was created and validated for hot air drying of corn grains. For this purpose, five independent groups were recognized, and then a dimensionless model was established to describe the effects of the independent $\pi$ terms on the dependent $\pi$ term. The validation results showed that MBE, $\mathrm{R}^{2}$, and RMSE were calculated as $0.0648,0.85$, and 0.018, respectively (Moradi and Karparvarfard, 2016).

\section{Conclusion}

In the present research, a solar cabinet dryer was employed for exploring the drying kinetics of lemon verbena. To describe the dried materials' quality, the extracted material's essential oil contents were analyzed using the GC-MS method. The leaves' drying behavior was studied by a new dimensionless model, which became established and validated. The drying kinetics results revealed that shorter drying time could be obtained at higher drying temperatures, air velocity, and mesh size. Also, the essential oil content reduced as air temperature and velocity increased. However, essential oil content and composition increased parallel to the increase in mesh size. Therefore, the most effective drying variable that can be modified to shorten the drying time while increasing the essential oil content is recognized as a mesh tray size. The validation results of the dimensionless model revealed that the obtained model could predict the drying kinetics of lemon verbena conveniently.

\section{References}

Agah, M. and Najafian, S., 2012. Essential oil content and composition of Lippa citriodora as affected by drying method before flowering stages. European Journal of Experimental Biology 2(5): 1771-1777.

Akbulut, A. and Durmuş, A., 2010. Energy and exergy analysis of thin-layer drying of mulberry in a forced solar dryer. Energy 35(4): 1754-1763. https://doi.org/10.1016/j.energy.2009.12.028

Akpinar, E.K., 2010. Drying of mint leaves in a solar dryer and under open sun: modelling, performance analysis. Energy Conversion and Management 51(12): 2407-2418. https://doi.org/10.1016/j. enconman.2010.05.005

Amer, B.M.A., Hossain, M.A. and Gottschalk, K., 2010. Design and performance evaluation of a new hybrid solar dryer for banana. Energy Conversion and Management 51(4): 813-820. https:// doi.org/10.1016/j.enconman.2009.11.016

Argyropoulos, D. and Müller, J., 2014. Changes of essential oil content and composition during convective drying of lemon balm (Melissa officinalis L.). Industrial Crops and Products 52: 118124. https://doi.org/10.1016/j.indcrop.2013.10.020

Bagheri, H., Arabhoseini, A. and Kianmehr, M.H., 2015. Energy and exergy analysis of thin-layer drying of tomato in a forced solar dryer. Iranian Journal of Biosystems Engineering 46(1): 39-45.

Bal, L.M., Satya, S. and Naik, S.N., 2010. Solar dryer with thermal energy storage systems for drying agricultural food products: a review. Renewable and Sustainable Energy Reviews 14(8): 22982314. https://doi.org/10.1016/j.rser.2010.04.014

Basti, A., Misaghi, A. and Khaschabi, D., 2007. Growth response and modelling of the effects of Zataria multiflora Boiss. essential oil, pH and temperature on Salmonella Typhimurium and Staphylococcus aureus. LWT Food Science and Technology 40(6): 973-981. https://doi.org/10.1016/j.lwt.2006.07.007

Benitez, J., 2016. Principles and modern applications of mass transfer operations. John Wiley \& Sons, New York.

Dehghani Mashkani, M.R.D., Larijani, K., Mehrafarin, A. and Badi, H.N., 2018. Changes in the essential oil content and composition of Thymus daenensis Celak. under different drying methods. Industrial Crops and Products 112: 389-395. https:// doi.org/10.1016/j.indcrop.2017.12.012

Ebadi, M.T., Azizi, M., Sefidkon, F. and Ahmadi, N., 2015. Influence of different drying methods on drying period, essential oil content and composition of Lippia citriodora Kunth. Journal of Applied Research on Medicinal and Aromatic Plants 2(4): 182187. https://doi.org/10.1016/j.jarmap.2015.06.001

El-Sebaii, A.A. and Shalaby, S.M., 2012. Solar drying of agricultural products: a review. Renewable and Sustainable Energy Reviews 16(1): 37-43. https://doi.org/10.1016/j.rser.2011.07.134

Eric, O., Loubiere, K., Martin, C., Delaplace, G., and Marc, A. (2015). Critical agitation for microcarrier suspension in orbital shaken bioreactors: Experimental study and dimensional analysis. Chemical Engineering Science, 122, 545-554.

Esfahani, J.A., Majdi, H. and Barati, E., 2014. Analytical two-dimensional analysis of the transport phenomena occurring during convective drying: apple slices. Journal of Food Engineering 123: 87-93. https://doi.org/10.1016/j.jfoodeng.2013.09.019 
Eswara, A.R. and Ramakrishnarao, M., 2013. Solar energy in food processing-a critical appraisal. Journal of Food Science and Technology 50(2): 209-227. https://doi.org/10.1007/s13197-0120739-3

Ezugwu, C.N., 2015. Renewable energy resources in Nigeria: sources, problems and prospects. Journal of Clean Energy Technologies 3(1): 68-71. https://doi.org/10.7763/JOCET.2015. V3.171

Golmakani, M. T., Farahmand, M., Ghassemi, A., Eskandari, M. H. and Niakousari, M. (2017). Enrichment of citral isomers in different microwave-assisted extraction of essential oil from fresh and dried lemon verbena (Aloysia citridora) leaves. Journal of Food Processing and Preservation, 41(6), e13215. https://doi. org/10.1111/jfpp.13215

Harrison, L., 2012. RHS Latin for gardeners. Mitchell Beazley, p. 224, London.

Hasan, A.A.M., Bala, B.K. and Rowshon, M.K., 2014. Thin layer drying of hybrid rice seed. Engineering in Agriculture, Environment and Food 7(4): 169-175. https://doi.org/10.1016/j. eaef.2014.06.002

Ho, Q.T., Carmeliet, J., Datta, A.K., Defraeye, T., Delele, M.A., Herremans, E., et al. 2013. Multiscale modeling in food engineering. Journal of Food Engineering 114(3): 279-291. https:// doi.org/10.1016/j.jfoodeng.2012.08.019

Infante, R., Rubio, P., Contador, L. and Moreno, V., 2010. Effect of drying process on lemon verbena (Lippia citrodora Kunth) aroma and infusion sensory quality. International Journal of Food Science \& Technology 45(1): 75-80. https://doi. org/10.1111/j.1365-2621.2009.02105.x

Jangam, S.V., Visavale, G.L. and Mujumdar, A.S., 2011. Use of renewable source of energy for drying of FVF. Drying of Foods, Vegetables and Fruits 3: 103-126.

Jiang, J., Dang, L., Tan, H., Pan, B. and Wei, H., 2017. Thin layer drying kinetics of pre-gelatinized starch under microwave. Journal of the Taiwan Institute of Chemical Engineers 72: 10-18. https://doi.org/10.1016/j.jtice.2017.01.005

Karparvarfard, S.H. and Rahmanian Koushkaki, H., 2015. Development of a fuel consumption equation: test case for a tractor chisel-ploughing in a clay loam soil. Biosystems Engineering 130: 23-33. https://doi.org/10.1016/j.biosystemseng.2014.11.015

Macfoy, C., 2013. Medicinal plants and traditional medicine in Sierra Leone. iUniverse, Indiana.

Vladut, V., 2010. Solar energy use in dryers as an alternative energy source in agriculture. Bulletin UASVM Agriculture 67(1): 187-193. http://dx.doi.org/10.15835/buasvmcn-agr:5031

Moradi, M. and Karparvarfard, S.H., 2016. Mathematical modeling of a corn grains drying process in a continuous dryer including inert particles. Iranian Journal of Chemical Engineering 14(83): $82-90$.

Moradi, M., Niakousari, M. and Etemadi, A., 2016. Dimensionless modeling of thin-layer drying process of Aloe vera gel. Iranian Food Science and Technology Research Journal 12: 362-370. https://doi.org/10.22067/ifstrj.v12i3.55168
Moradi, M., Niakousari, M. and Mousavi Khaneghah, A., 2019. Kinetics and mathematical modeling of thin-layer drying of osmo-treated Aloe vera (Aloe barbadensis) gel slices. Journal of Food Process Engineering 42(6): e13180. https://doi. org/10.1111/jfpe.13180

Morton, C.O., Wurster, S., Fliesser, M., Ebel, F., Page, L., Hünniger, K., et al. 2018. Validation of a simplified in vitro Transwell ${ }^{\circ}$ model of the alveolar surface to assess host immunity induced by different morpho-types of Aspergillus fumigatus. International Journal of Medical Microbiology 309(8): 10091017. https://doi.org/10.1016/j.ijmm.2018.09.001

Mujumdar, A.S. and Jangam, S.V., 2011. Energy issues and use of renewable source of energy for drying of foods. In: Proceedings of the International Workshop on Drying of Food and Biomaterials, Bangkok, Thailand.

Ndukwu, M.C., 2009. Effect of drying temperature and drying air velocity on the drying rate and drying constant of cocoa bean. Agricultural Engineering International: The CIGR Journal XI: 1091.

Perrot, N., Trelea, I.C., Baudrit, C., Trystram, G. and Bourgine, P., 2011. Modelling and analysis of complex food systems: state of the art and new trends. Trends in Food Science \& Technology 22(6): 304-314. https://doi.org/10.1016/j.tifs.2011.03.008

Putra, R.N. and Ajiwiguna, T.A., 2017. Influence of air temperature and velocity for drying process. Procedia Engineering 170: 516519. https://doi.org/10.1016/j.proeng.2017.03.082

Sodom and-Moghaddam, S., Sharifi, M., Zareiforoush, H. and Mobli, H., 2020. Mathematical modeling of lemon verbena leaves drying in a continuous flow dryer equipped with a solar pre-heating system. Quality Assurance and Safety of Crops \& Foods 12(1): 57-66. https://doi.org/10.15586/QAS2019.658

Tahmasebi, M., Tavakoli Hashjin, T., Khoshtaghaza, M.H. and Nikbakht, A.M., 2011. Evaluation of thin-layer drying models for simulation of drying kinetics of quercus (Quercus persica and Quercus libani). Journal of Agriculture, Science and Technology 13(2): 155-163.

Rocha, R.P., de Castro Melo, E., Demuner, A.J., Radünz, L.L. and Braun, H., 2012. Effect of drying air velocity on the quality of essential oil from lemongrass. Global Science and Technology 5(1): 23-31.

Santacatalina, J.V., Soriano, J.R., Cárcel, J.A. and Garcia-Perez, J.V., 2016. Influence of air velocity and temperature on ultrasonically assisted low temperature drying of eggplant. Food and Bioproducts Processing 100: 282-291. https://doi.org/10.1016/j. fbp.2016.07.010

Trystram, G., 2012. Modelling of food and food processes. Journal of Food Engineering 110(2): 269-277. https://doi.org/10.1016/j. jfoodeng.2011.05.001

Zomorodian, A. and Moradi, M., 2010. Mathematical modeling of forced convection thin layer solar drying for Cuminum cyminum. Journal of Agriculture, Science and Technology 12: 401-408. 